\title{
Characterization of road freight transportation and its impact on the national emission inventory in China
}

\author{
X. F. Yang, H. Liu, H. Y. Man, and K. B. He \\ State Key Joint Laboratory of Environment Simulation and Pollution Control, School of Environment, Tsinghua University, \\ Beijing, China
}

Correspondence to: H. Liu (liu_env@tsinghua.edu.cn) and K. B. He (hekb@tsinghua.edu.cn)

Received: 23 May 2014 - Published in Atmos. Chem. Phys. Discuss.: 11 June 2014

Revised: 12 December 2014 - Accepted: 26 January 2015 - Published: 26 February 2015

\begin{abstract}
Diesel trucks are major contributors of nitrogen oxides $\left(\mathrm{NO}_{\mathrm{x}}\right)$ and primary particulate matter smaller than $2.5 \mu \mathrm{m}\left(\mathrm{PM}_{2.5}\right)$ in the transportation sector. However, there are more obstacles to existing estimations of diesel-truck emissions compared with those of cars. The obstacles include both inappropriate methodology and missing basic data in China. According to our research, a large number of trucks are conducting long-distance intercity or interprovincial transportation. Thus, the method used by most existing inventories, based on local registration number, is inappropriate. A road emission intensity-based (REIB) approach is introduced in this research instead of registrationpopulation-based approach. To provide efficient data for the REIB approach, 1060 questionnaire responses and approximately 1.7 million valid seconds of onboard GPS monitoring data were collected in China.

The estimated $\mathrm{NO}_{\mathrm{x}}$ and $\mathrm{PM}_{2.5}$ emissions from diesel freight trucks in China were 5.0 (4.8-7.2) million tonnes and $0.20(0.17-0.22)$ million tonnes, respectively, in 2011. The province-based emission inventory is also established using the REIB approach. It was found that the driving conditions on different types of road have significant impacts on the emission levels of freight trucks. The largest differences among the emission factors (in $\mathrm{g} \mathrm{km}^{-1}$ ) on different roads exceed 70 and $50 \%$ for $\mathrm{NO}_{\mathrm{x}}$ and $\mathrm{PM}_{2.5}$, respectively. A region with more intercity freeways or national roads tends to have more $\mathrm{NO}_{\mathrm{x}}$ emissions, while urban streets play a more important role in primary $\mathrm{PM}_{2.5}$ emissions from freight trucks. Compared with the inventory of the Ministry of Environment Protection, which allocates emissions according to local truck registration number and neglects interregional long-distance transport trips, the differences for $\mathrm{NO}_{\mathrm{x}}$ and
\end{abstract}

$\mathrm{PM}_{2.5}$ are +28 and $-57 \%$, respectively. The REIB approach matches better with traffic statistical data on a provincial level. Furthermore, the different driving conditions on the different roads types are no longer overlooked with this approach.

\section{Introduction}

China has been facing severe air-quality challenges in the past several years. Air pollution in China not only endangers the health of billions of people but also creates a substantial burden on the economy (Matus et al., 2012). The 2005 marginal welfare impact to China, considering only ozone and particulate matter, was USD 112 billion (1997 USD) (Hammitt and Zhou, 2006). Vehicular emissions form one of the greatest contributors to the air pollution in China, especially of $\mathrm{NO}_{\mathrm{x}}$ and $\mathrm{PM}_{2.5}$. According to the Ministry of Environmental Protection (MEP), vehicular emissions contributed $27.4 \%$ of the total $\mathrm{NO}_{\mathrm{x}}$ emissions in 2012 (MEP, 2012a). Vehicle emissions also contribute more than $30 \%$ of $\mathrm{PM}_{2.5}$ in Beijing, as announced by the Beijing government.

Preparing inventories is essential to the assessment and management of current atmospheric problems (Ohara et al., 2007; Streets et al., 2003; Beaton et al., 1995). Among all the sources, the vehicle emissions source is one with the greatest uncertainty and ambiguity (Cai and Xie, 2007; Wang et al., 2008a). Among all vehicles, diesel freight trucks contributed to a large portion of vehicular emissions. According to the MEP, diesel vehicles, mainly consisting of freight trucks, contributed $70 \%$ of $\mathrm{NO}_{\mathrm{x}}$ and $90 \%$ of $\mathrm{PM}$ of the total vehicular emissions in 2012 (MEP, 2012a). Therefore, improving 
current emission inventory and reducing the uncertainty is of great necessity.

Another major impediment to developing a new approach to estimate freight-truck emissions is that most inventories were based on the local registration numbers, which means there is an assumption that trucks are running within the province or city where they registered (Zheng et al., 2013). However, according to this research, many trucks are conducting long-distance intercity or interprovincial transportation trips. Therefore, a road-based estimate approach was introduced in this research instead of the former local registration-number-based approach. This simulation addresses more on the freight transportation system as a whole rather than a local emissions scale.

In summary, we attempt to identify and reduce the impact of the factors mentioned above by adopting a road-based approach with collected activity-level data including both questionnaire answers and Global Positioning System (GPS) records. In particular, this research serves to (1) provide more accurate activity-level data for freight trucks, including mileage traveled versus age, activity regions and driving conditions; (2) identify the different emission rates caused by different driving conditions on each type of road; and (3) provide a national emissions inventory that considers the road freight system as whole instead of separating it into different pieces according to the provincial divisions.

\section{Data and methodology}

\subsection{Data source}

The data source of this research primarily consists of two major parts: (1) questionnaires that investigated the driving behavior of professional truck drivers, along with experiential data that related to their driving pattern, and (2) driving condition tests of trucks driving on different types of roads. Information about the questionnaires and GPS data, such as the sample numbers and location range, is shown in Table 1.

A series of questions related to driving pattern, fuel consumption, route selection, transport range, etc., were included in the questionnaires. All the investigated drivers are professional freight-truck drivers. Because most of the freight-truck drivers are not highly educated, all the questionnaires were conducted by college students, and a detailed explanation was required to make sure that the drivers understood the question correctly. To ensure the quality of the answers, related questions that validate each other are designed to identify careless or wrong answers. A total of 1060 samples from 16 provinces were investigated. Therefore, it is a large sample study according to the theory of statistics (Box et al., 2005). Previous studies on driver behavior in China also conducted questionnaire investigations. For example, 520 samples, targeted at all automobile drivers and not limited to trucks, were studied in 2002 to understand the behav- ior of drivers (Xie and Parker, 2002). Another 87 completed samples were used to make comparisons between China and Hong Kong in 2009 (Chan et al., 2009). Questionnaires are also used on truck drivers in Australia $(N=433)$, Germany $(N=10101)$, Brazil $(N=4878)$ and New Zealand (1065) for different purposes (Sullman et al., 2002; Lajunen et al., 2004; Moreno et al., 2004, 2006). Compared with other sample sizes of domestic and foreign studies on truck drivers, the number of samples in this study is adequate to describe the average level of freight-truck activities.

Trucks are classified into four types according to weight in this research, following the guidelines of the National Statistics Bureau (CATARC, 2012): mini trucks (MiniT) with weights less than $1.8 \mathrm{t}$, light-duty trucks (LDT) with weights of 1.8-6 t, middle-duty trucks (MDT) with weights of 6-14t and heavy-duty trucks (HDT) with weights greater than $14 \mathrm{t}$. The classification is used to get vehicle stock from national statistics, questionnaires investigation and data analysis in this study. Because the MiniT population only consists of a very small proportion of the total truck fleet, approximately $0.98 \%$ of the total freight-truck stock in 2011, and the differences between MiniT and LDT are not significant, MiniTs and LDTs are grouped together in the calculation of emission factors.

Because the normal method of testing driving patterns focuses on driving in cities, this method is less relevant to freight trucks; a freight truck has significant operation differences from that of a private passenger car (Holguin-Veras et al., 2006; Kamakaté and Schipper, 2009). Freight trucks in China generally travel between cities and do not stop for extended time periods, except for a small portion that run inside cities for short-distance freight transit or other special public services (like garbage collection or road sprinkler) (Hine et al., 1995). To obtain the real time driving patterns of freight trucks, a GPS receiver and speed sensor were used. For many years, GPS has been used to monitor the driving conditions of vehicles in many emission-related studies (Ochieng et al., 2003; Rakha et al., 2004; Canagaratna et al., 2004). A multifunction Columbus GPS data logger V-990 produced by GPSWebShop (Canada) Inc. was used in this research. The GPS data logger is set to automatically turn on or off when the engine of the investigated truck is turned on or off. Therefore, the data were collected every second that the engine of the truck under investigation was running. We were able to do this thanks to a sensor in the GPS that captured the voltage change in the cigarette lighter.

The investigated trucks were all driven by professional truck drivers during the tested time period. The GPS data logger was required to be used for at least 1 week to record the full driving pattern of the freight trucks. All drivers maintained their business as usual during the test time period. In total, 1728622 valid seconds from 16 trucks with different load capacities and functions were tested. All of the tested data were classified into five different types according to the road type they were on. The road type is identified by Google 
Table 1. Data information.

\begin{tabular}{llll}
\hline Data & Sample numbers & Region & Test time \\
\hline Questionnaires & 1060 & 16 provinces & August 2012-August 2013 \\
GPS data & 16 trucks/1 728 622 valid seconds & 15 provinces & June 2013-October 2013 \\
\hline
\end{tabular}

Maps. The roads are divided into five classifications: urban roads, rural/town road, provincial roads, national roads and intercity freeways. Typical speed tracks and routes of each type of the tested roads are shown in Fig. 1. To present the speed distribution in identical scales, only the first $4000 \mathrm{~s}$ of speed are shown in Fig. 1. For urban roads there are only 3989 s of data, and they represent the longest single trip in an urban area that was monitored in this research.

\subsection{Emission rates and emission factors}

Vehicle-specific power (VSP) is a concept that describes the working conditions, such as aerodynamic drag, acceleration, rolling resistance and hill climbing, of a vehicle and is used in the evaluation of vehicle emissions (Jimenez-Palacios, 1998). VSP is now widely used in emission factor modeling, such as in the International Vehicle Emission (IVE) and Motor Vehicle Emission Simulator (MOVES) models. For the VSP calculation, the equation for heavy-duty diesel trucks (HDDTs) from the MOVES model was applied in this study (Eq. 1):

$\mathrm{VSP}=\frac{A}{m} \cdot v+\frac{B}{m} \cdot v^{2}+\frac{C}{m} \cdot v^{3}+a \cdot v+g v \cdot \sin \theta$,

where $m$ is the vehicle weight in tonnes; $v$ is the instantaneous vehicle speed, $\mathrm{ms}^{-1} ; a$ is the instantaneous vehicle acceleration, $\mathrm{m} \mathrm{s}^{-2} ; \theta$ is the road grade, radians; $A$ is the rolling resistance coefficient, $\mathrm{kW} \mathrm{s} \mathrm{m}^{-1} ; B$ is the rotational resistance coefficient, $\mathrm{kW} \mathrm{s} \mathrm{m}^{-2}$; and $C$ is the aerodynamic drag coefficient, $\mathrm{kW} \mathrm{s} \mathrm{m}^{-3}$. The road-load coefficients (i.e., $A, B$ and $C$ ) of each major category are shown in Table 2 . The coefficients were estimated according to the typical weight type used in the MOVES model (Koupal et al., 2005).

Engine stress (ES), which includes $25 \mathrm{~s}$ historical VSP data, was introduced by emission models such as the IVE model to represent how early running conditions impact current emissions. ES is calculated in the following equation (Eq. 2) from the IVE model (CE-CERT et al., 2008):

$\mathrm{ES}=\mathrm{RPMIndex}+\left(0.08 \mathrm{tkW}^{-1}\right) \times$ PreaveragePower,

where PreaveragePower is the average VSP during -5 to $-25 \mathrm{~s} \mathrm{~kW}^{-1} \mathrm{t}^{-1}$; RPMIndex is the Velocity ${ }_{t}=$ $0 /$ SpeedDivider, unitless; and the minimum RPMIndex is 0.9. The detailed SpeedDivider is shown in Table S1 in the Supplement.

Operating mode bins are identified according to the VSP and ES. Data from multiple researches were used to obtain the representative emission rates in this research since no study provides sufficient data of emission rates for all types of trucks. Emission rates of each bin from Liu's study (Liu et al., 2009) were used to generate curves of emission versus bins, what we called bin-emission curves. Emission factors of different vehicle classes from Wang et al. (2012), Wu et al. (2012) and Zhang et al. (2013) were used to amend the bin-emission curves, moving the curves up or down without changing the relative relationship among bins. The outcome representative emission rates of each bin are shown in Fig. S1. With GPS monitoring data from tested trucks in this research, distance-specific emission factors can be calculated with the following equation (Eq. 3):

$\mathrm{EF}_{i, j}=\frac{1000 \cdot \sum_{\mathrm{t}} \mathrm{ER}_{i, j, t}}{\sum_{t} v_{i, j, t}}$,

where EF is the distance-specific emission factor, $\mathrm{g} \mathrm{km}^{-1}$; $\mathrm{ER}$ is the second-by-second emission rate, $\mathrm{g} \mathrm{s}^{-1}$; and $v$ is the velocity. The subscripts $i, j$ and $t$ represent road type, type of tested truck and time, respectively.

\subsection{Setting up the regional emission inventory}

Top-down approaches are widely used in estimating anthropogenic emissions for a relatively large geographic range. According to the annual vehicle population numbers from the China's Automotive Industrial Statistics Yearbook (CATARC, 2012) and the survival curve from a former study (Hao et al., 2011), details about the existing vehicle population, such as the portion of trucks at different ages and weight, can be calculated. Following the Yearbook, the trucks were divided into four types according to their gross vehicle weight $(\mathrm{GVW})$ (shown in Table 2). In addition, the annual vehicle kilometers traveled (VKT) of trucks at different ages is acquired from the investigation. Combining the fleet information and the VKT data together yields the total activitylevel number.

In this research, a new road emission intensitybased (REIB) approach was introduced to calculate the regional emission inventory of diesel trucks. Instead of relying on local registration numbers, the road emission intensity served as the base of the REIB approach. The basic assumption for REIB is that for freight trucks, the driving conditions and truck flow were similar on the same type of road in different regions. The emission intensity of different types of road was calculated according to the activity distribution obtained 

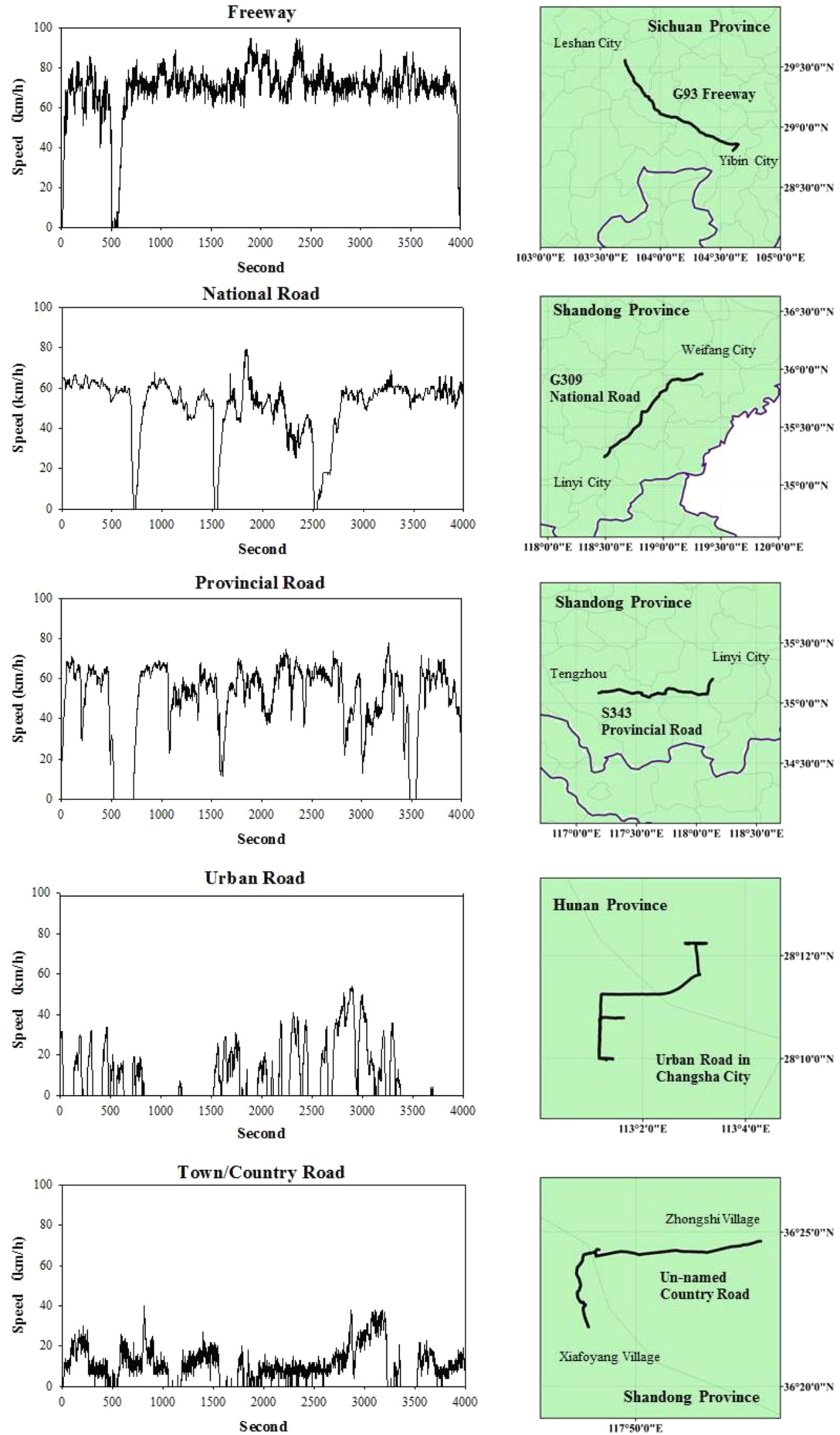

Figure 1. Speed and route of different types of tested roads.

from this research. Then, the emissions in each grid cell or province could be calculated according to the length of different types of road. Unlike former approaches that assumed that truck operation was limited to the region where they are registered, the REIB approach examines the road freight transportation as a nationwide system. The REIB approach is a better fit, given the fact that a large portion of trucks run across provinces. In the GPS monitoring conducted in this research, the longest single trip traveled across eight provinces. The local registration-based approach introduces great inaccuracy by overlooking the cross-region trips of freight trucks. 
Table 2. Summary of road-load coefficient values for calculating VSP of each truck category.

\begin{tabular}{lrrrr}
\hline & MiniT & LDT & MDT & HDT \\
\hline Vehicle type & LIGHT & LIGHT & HEAVY & HEAVY \\
GVW (tonnes) & $<=1.6$ & $(1.6,6]$ & $(6 \sim 14]$ & $>14$ \\
Mileage correction factor & 0.145 & 0.475 & 1.278 & 2.713 \\
Typical GVW (tonnes) & 3.3 & 10.2 & 17.6 \\
$A / m$ & 0.102 & 0.0875 & 0.0661 \\
$B / m$ & 0.00131 & 0 & 0 \\
$C / m$ & 0.000322 & 0.000248 & 0.000207 \\
\hline
\end{tabular}

Note: with reference to the MOVES model, those vehicle types and coefficients are estimated according to the typical gross vehicle weight (GVW) (Koupal et al., 2004). The classification of truck type is explained in Sect. 2.1.

Different types of trucks were investigated to determine their traveling information. The drivers were asked to estimate the distance portion that they drive on different types of roads. In this study, the roads are classified into freeway, national roads, provincial roads, rural roads, urban roads and other special roads such as those within factories and ports. Then, the emission density of different types of roads was calculated according to following Eq. (4):

$\rho_{i}=$

$\frac{\sum_{j, k} \overline{\mathrm{VKT}}_{j, k} \cdot \mathrm{NV}_{\text {current_year }}-k, j \cdot \mathrm{SR}_{j, k} \cdot \mathrm{EF}_{i, j, k} \cdot \mathrm{DP}_{i, j}}{L_{i}}$,

where $\rho_{i}$ is the emission density of $i$ type road, $\mathrm{g} \mathrm{km}^{-1} \mathrm{yr}^{-1}$; $\overline{\mathrm{VKT}}_{j, k}$ is the average VKT per vehicle, $\mathrm{kmyear}^{-1}$; $\mathrm{NV}_{\text {current_year }}-k, j$ is the new vehicle population of type $j k$ years ago; $\mathrm{SR}_{j, k}$ is the survival rate of a $k$-year-old type $j$ vehicle (data came from nationwide vehicle survival pattern research conducted by Hao el al., 2011, and the survival curves are shown in Fig. S2); $\mathrm{DP}_{i, j}$ is the distance portion for type $j$ truck running on type $i$ road; and $L_{i}$ is the total length of type $i$ road in China, $\mathrm{km}$. The subscript $k$ refers to the age of a vehicle. The remaining variables are the same as described above.

With the emission-density number, the national emissions inventory can be calculated according to the spatial distribution of different types of road. In this research, multidimensions of inventories have been created to present the spatial distribution of freight-truck emissions.

\section{Results and discussion}

\subsection{Activity level of freight trucks}

Freight trucks with different ages were investigated in this research. According to a former study, the total distance that a passenger car traveled has a quadratic relationship to its age (Liu et al., 2008). This relationship means that as the passenger car ages, the mileage traveled per year decreases. According to the investigated samples in this study, the average total kilometers that a truck traveled also follow the similar pattern (shown in Fig. 2). With an $R$-squared value of 0.9651 , the empirical quadratic equation is adequate to describe the average activity level. The standard error in this research is relatively high compared to passenger cars, revealing large variation among the trucks of the same age. This significant variation is caused by the diversity of functions of different trucks, which makes the investigation of truck activity a difficult task. However, the investigation result is the only data available to understand the characteristics of trucks at different ages. Moreover, unlike former research that used average mileage traveled for the entire fleet (Huo et al., 2012b; Fu et al., 2001), these results represent the aging effect of trucks, namely that the annual mileage decreases as the truck grows older. By neglecting the annual mileage reduction as trucks age, the impact of old trucks may be exaggerated because they do not actually run as much as newer trucks. Therefore, this investigation will help to identify the contribution of trucks under different ages more accurately.

Moreover, mileage correction factors by vehicle type were introduced to identify the differences between each type of truck, as shown in Table 2. The correction factors were the ratio of the average kilometers traveled of a certain type of truck versus the entire truck fleet. From the value of correction factors we can see that as GVW grows, the average kilometers traveled increase.

Both the mileage traveled and emission rates for trucks of different ages are different. Therefore, it is required to have the detailed age composition of the truck fleet in the target year. The fleet composition and the total mileage traveled in 2011 by vehicle age are shown in Fig. 3a and b. The total diesel-truck population in 2011 reached 193.3 million, of which 53\% came online during 2009-2011 and therefore met the China 3 tailpipe emissions standard. The Chinese government adopted vehicle emission standards following emission standards in Europe in 1999. The emission levels 1 to 3 in China are equivalent to Euro 1 to 3 standards, while China 0 means no emission control was applied. The limits of $\mathrm{NO}_{\mathrm{x}}$ and PM based on China vehicle emission standards are shown in the Supplement, Table S2. Truck population in China experienced a tremendous growth during 2009-2011 according to data from the National Statistical Bureau of China. In 2009, 0.98 million more new trucks entered the market than in 2008, which was equivalent to $8.7 \%$ of the total truck stock in 2008. Most of the 2009-2011 trucks survived in the 2011 market. Therefore, there was an obvious excess of trucks from 2009 to 2011 in the 2011 market compared with previous years. Different from the vehicle population, the total mileage contributed by the China 3 trucks reached $60 \%$ because new trucks are more frequently used. A total of 1.47 trillion kilometers were driven by diesel freight trucks in 2011. The large number of new vehicles, in both population number and mileage traveled, indicates that the application of stricter emissions standards, because China is experiencing a boom in its truck population, has 


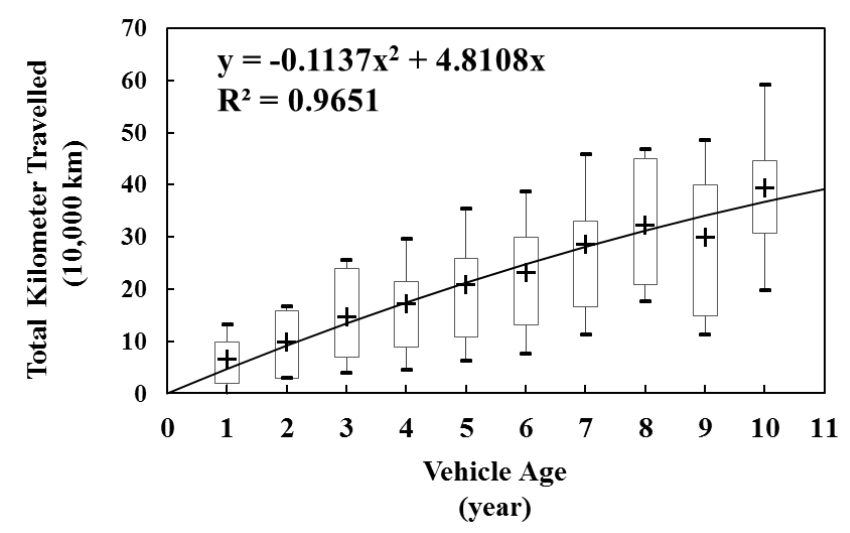

Figure 2. Accumulated traveled distance of trucks plotted against different ages (the boxes show the first and third quartiles of the total investigated numbers and the bars show the standard errors).

great significance. However, the application of the China 4 emissions standard on diesel vehicles has been delayed because oil companies in China were unable to supply diesel that met the standard (Zhang et al., 2012). Considering the booming increase of new diesel trucks and the large share of them in the total mileage traveled, the impact of the delay of upgrading the emissions standard would be highly significant.

One of the challenges in mapping the emissions of freight trucks is that it is hard to identify where the trucks are running. The problem is more challenging with trucks than with other types of automobiles because trucks are not limited to their registration region as cars are nor do they have fixed routes as buses do. In the questionnaires conducted in this research, the professional truck drivers estimated the length proportions they drive on different types of road. The length proportions of roads that trucks run on are summarized in different groups according to their GVW in Fig. 4. As Fig. 4 shows, we determined that different types of trucks tend to have different running patterns. It is obvious that heavier trucks are more likely to run on the high-speed freeways; heavy-duty trucks are generally employed for long-distance transportation because they are more economical than lighter carriers. For long-distance transportation, high-speed freeways are the primary options for the drivers. Contrarily, inside an urban area, mini-trucks and light-duty trucks are more common given their flexibility and also possible constrictions on heavy-duty trucks. This result is used to estimate the truck flow and fleet composition and to assign total kilometers traveled for each type of truck. The mileage and fleet information on each type of road are inputs for the calculation of emission intensity. The differences of fleet compositions between the different types of road have long been overlooked in past inventory work.

\subsection{Different driving characters on different types of roads}

Trucks with different weights usually serve different purposes. This consequently leads to different driving patterns of the different types of trucks. According to the research results, the annual mileage traveled and average speed have significant differences among the different types of trucks.

Generally, heavier trucks ran at higher speeds and traveled greater mileage than lighter trucks. This behavior is due to the varying main function of trucks with different load capacities. Heavier trucks are usually used for long-distance transportation to reduce average cost, which means heavier trucks operate more on high-speed roads. Lighter trucks run more on urban roads because of their flexibility. The differences in running times on each type of road compared between the different trucks are shown in Fig. 4. These differences lead to different driving patterns for the different types of trucks. As shown in Fig. 1, the speed records on selected routes for each type of road were quite different. For the tested route on the G93 freeway, the average speed was maintained at approximately $70 \mathrm{~km} \mathrm{~h}^{-1}$ and the stop times (when the speed reaches 0 ) were rare. It indicated that the traffic flow on the G93 freeway during the tested time was very fluid. For the tested routes on the G309 national road and S343 provincial road, the speed rarely exceeded $70 \mathrm{~km} \mathrm{~h}^{-1}$, and the stops and sudden drops in speed were more frequent than on the G93 freeway. Although the speed distributions on the G309 and S434 looked similar, the speed on the S434 obviously fluctuated more frequently than that on the G309. This revealed that the driving conditions on these two roads were similar, while traffic flow on the G309 was more fluent. For the urban road in Changsha, Hunan, it was difficult for the truck to reach $40 \mathrm{~km} \mathrm{~h}^{-1}$ during the tested time. Stops were much more frequent than on former roads potentially due to traffic lights and traffic jams within the city. As for the country road between two villages in Shandong, the driving conditions were the worst among all the roads. The maximum speed during the tested time period was $40 \mathrm{~km} \mathrm{~h}^{-1}$, and $85.5 \%$ of time the speed stayed below $20 \mathrm{~km} \mathrm{~h}^{-1}$. In summary, the selected examples roads show that the driving conditions were distinctly different.

To demonstrate that the differences were not special cases, a statistical summary was made to see whether significant differences could be found in the large amount of data that we collected. The velocity and acceleration distributions for the total monitored data on urban roads (226290 valid seconds) and freeways (583 922 valid seconds) are shown in Fig. 5 as selected examples to illustrate the differences between the running conditions on these two types of roads (monitoring data on other roads are shown in Figs. S3-S5). Velocity and acceleration are divided into several bins, and the frequency of each bin is calculated. Velocity is divided into 30 bins from 0 to $30 \mathrm{~m} \mathrm{~s}^{-1}$, and acceleration is divided into seven bins from -1.5 to $2 \mathrm{~m} \mathrm{~s}^{-2}$. 


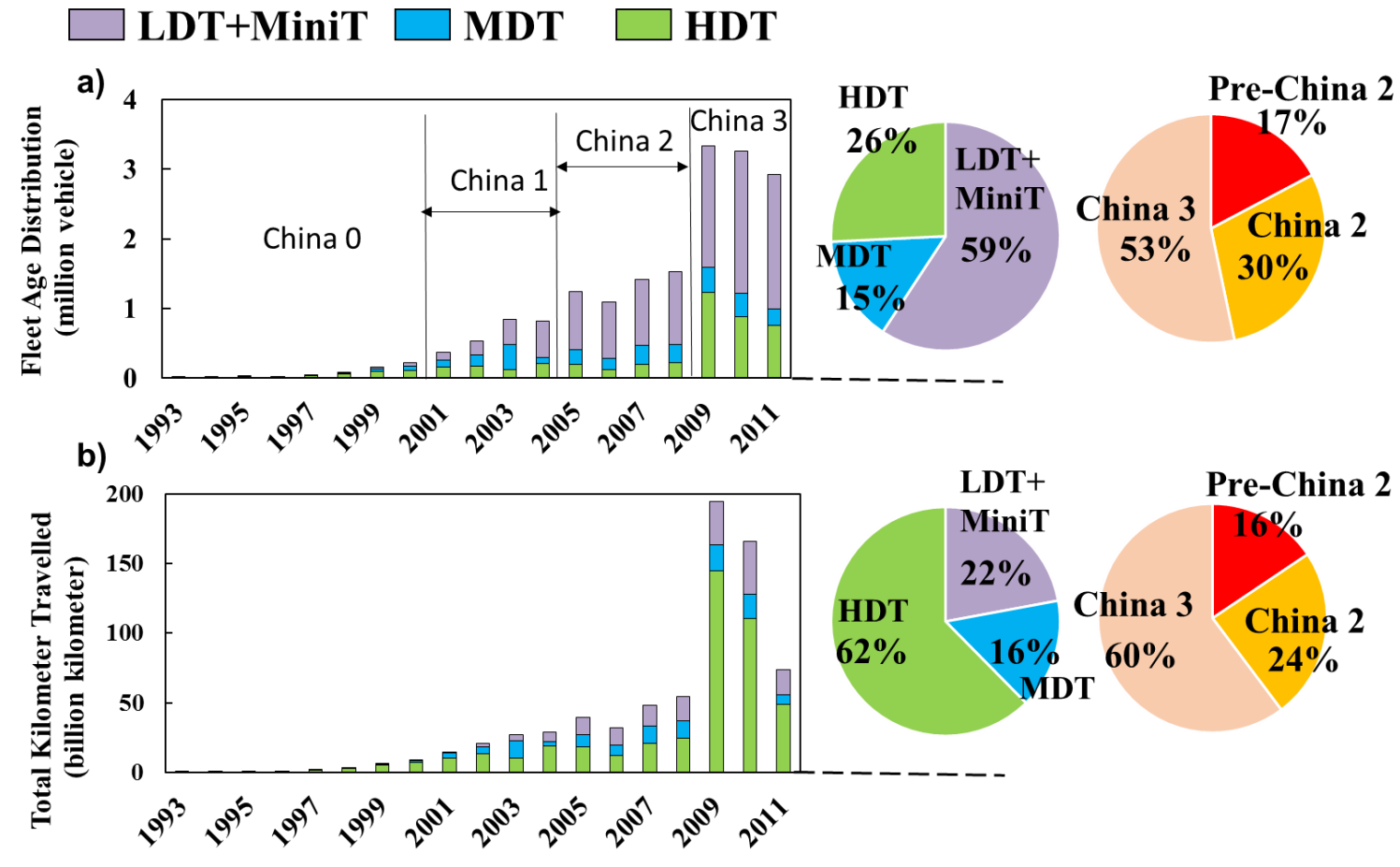

Online Year of Truck

Figure 3. Distribution of age and total mileage traveled of the diesel-truck fleet in 2011, China: (a) vehicle population and (b) total mileage.

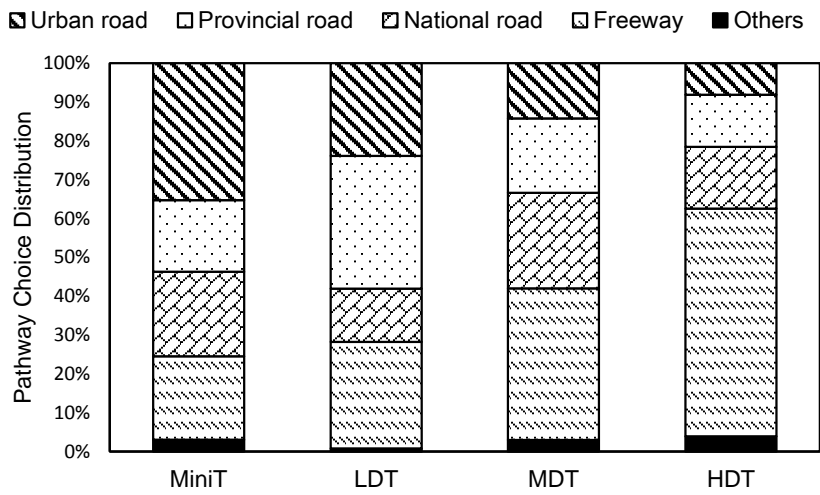

Figure 4. Proportion of running times on different types of roads.

The results show two obviously different running conditions on the urban roads and intercity freeway. The average speed and the maximum speed on the urban road are much lower than that on the intercity freeways. Additionally, the urban road has much greater low-speed running and idling time. If the high peak of the low-speed zone is removed, the speed distribution on the urban road is relatively flat with a range of 5 to $20 \mathrm{~m} \mathrm{~s}^{-1}$. On the other hand, the situation on the intercity freeway is quite different. There are two peaks on the intercity freeway: a smaller peak in the lower-speed zone and a larger peak in the high-speed zone. The percentage of the middle speed is very low. From the results, it shows that the difference is still significant considering all the collected data from different roads and trucks. Because both velocity and acceleration affect the vehicle specific power and engine stress, different velocity and acceleration distributions lead to different emission results. Without considering the differences in emission factors caused by the different driving conditions, uncertainties and inaccuracy were introduced to former vehicular emissions inventory. In the upcoming section, the differences in emission factors on the different roads will be discussed.

\subsection{Emission differences caused by different driving cycles on each type of road}

As discussed in the previous section, different driving cycles on the different types of road lead to different emission factors. The IVE model is a widely accepted tool to estimate vehicle emissions, and previous research in China has already localized the IVE model so that it applies to the Chinese vehicles. The IVE model uses velocity and VSP as two inputs and classifies the driving conditions into different bins. For each bin, a measured typical emission factor is used to represent the average emission level. The distribution of bins on each type of road is shown in Fig. S6, and the emission factors that are derived for each type of the road using the IVE model are shown in Table 2. As introduced in Sect. 2.2, on-board measurement data in China were used to calculate the average 
a)

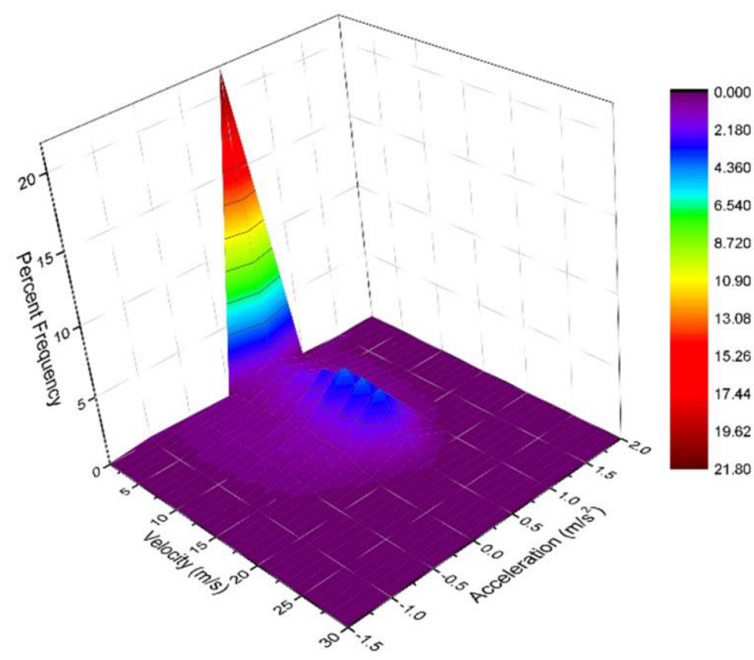

b)

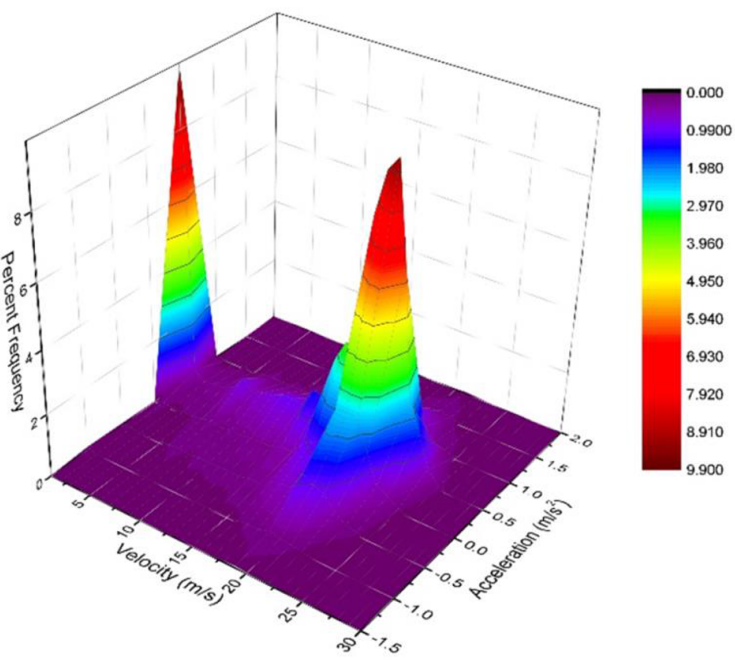

Figure 5. Velocity and acceleration distribution on each type of roads: (a) urban roads and (b) an intercity freeway.

emission factor on the different types of road with real-time monitoring GPS data. The results are shown in Fig. 6.

From the results, it can be concluded that running conditions on different types of road lead to significant differences in the emission factors. Generally, rural or town areas tend to have the worst conditions for diesel freight trucks. In almost all the cases, the emission factors for both $\mathrm{NO}_{\mathrm{x}}$ and $\mathrm{PM}_{2.5}$ on rural or town roads are the largest among the five types of roads. This is mainly due to the long idling time without shutting down the engine on the rural or town roads while loading or unloading. Generally, the highest emission factor is 73.5 and $51.2 \%$ higher than the lowest one for $\mathrm{NO}_{\mathrm{x}}$ and $\mathrm{PM}_{2.5}$, respectively. These differences will lead to equivalent scaling errors in the total emissions of freight trucks. Generally, the emission factors tested on urban roads where the driving conditions are relatively worse, leading to a higher emission factor. However, intercity national roads, provincial
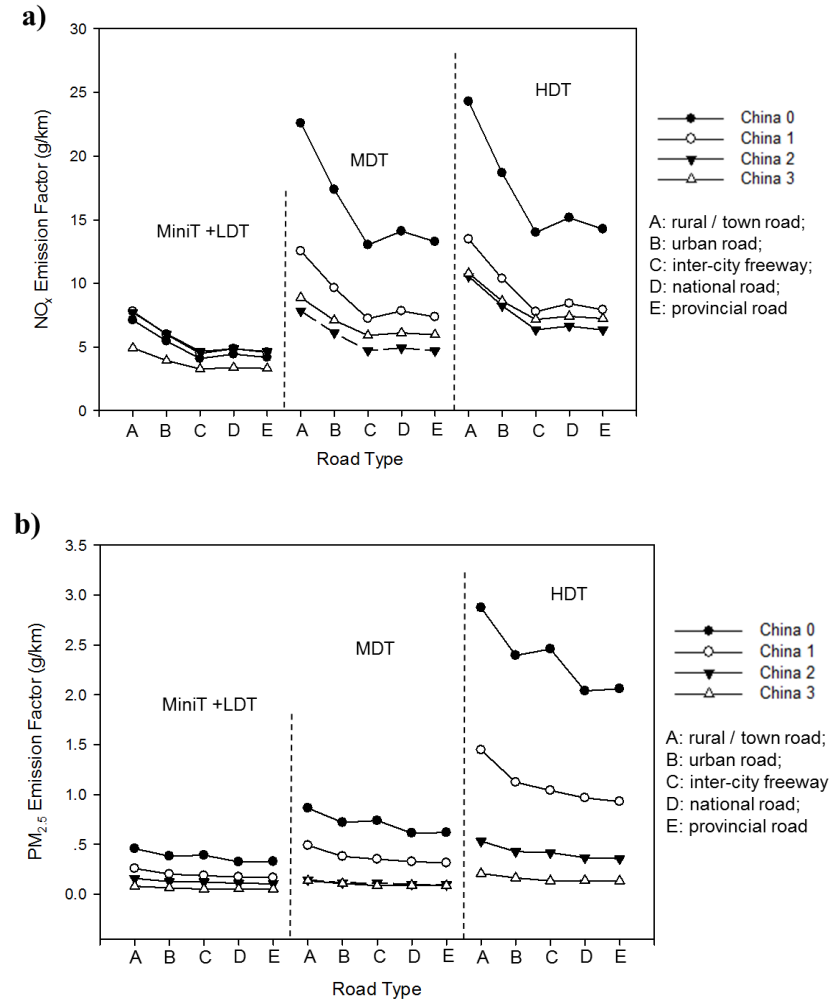

Figure 6. Emission factors on different roads: (a) $\mathrm{NO}_{\mathrm{x}}$ emission factors and (b) $\mathrm{PM}_{2.5}$ emission factors.

roads and freeways are also important places where many freight trucks run, especially those with heavier gross vehicle weights. This means previous studies have overestimated emissions from freight trucks, because when running on intercity roads or freeways, trucks have a lower emission factor due to better running conditions.

\subsection{Emission inventory of freight trucks}

According to this research, the total $\mathrm{NO}_{\mathrm{x}}$ from freight trucks in 2011 was 5 million tonnes. The primary $\mathrm{PM}_{2.5}$ emissions from diesel trucks in 2011 were $200000 \mathrm{t}$.

Figure 7 shows the $\mathrm{NO}_{\mathrm{x}}$ and $\mathrm{PM}_{2.5}$ emissions from trucks of different ages in the 2011 fleet. For both $\mathrm{NO}_{\mathrm{x}}$ and $\mathrm{PM}_{2.5}$, heavy-duty trucks accounted for over $70 \%$ of the total emissions despite only counting for $26 \%$ of the total population. Hence, focus should be placed on controlling the emissions from heavy-duty trucks. If the age of trucks is considered, the trucks that entered the market during 2009-2011 accounted for $40 \%$ of the total population and $60 \%$ of the total mileage traveled due to the mushrooming sales and the greater activity of new vehicles. This means the tightening of the emissions standard for new vehicles plays a critical role in the vehicular emissions control section. Moreover, yellowlabel vehicles, which are the pre-China-3-emissions-standard 
diesel vehicles, have a more significant contribution to primary $\mathrm{PM}_{2.5}$ emissions than $\mathrm{NO}_{\mathrm{x}}$.

Figure 8 shows the emissions distribution calculated according to the emission intensity of the different types of roads in the eastern part of China, where the major emissions occurred, with a resolution of $0.5 \times 0.5^{\circ}$ per cell. Unlike approaches that are based on the local registration numbers of trucks, the approach applied in this research relies on the assumption that the traffic volume of freight trucks on each type of road remains similar. This approach views the freight transport in the nation as a whole system. From the emissions map and the emission-intensity comparison, the freeways and national roads, where most of the freight transportation in China is conducted, have high emission intensities and emission impacts on their surroundings.

As shown in Fig. 8, freight transportation has the strongest impact in locations where the economy is well developed and the population has high density. The Beijing-Tianjin-Hebei (Jing-Jin-Ji) district, Yangtze River Delta and Pearl River Delta (PRD), the three biggest economic circles in China, are also the regions with the highest emission density. From another perspective, 12 out of the 13 key control regions listed in the 12th 5-year plan (FYP) of air-pollution control in China have relatively high emission densities, as shown in Fig. 8 (MEP et al., 2012b); the remaining key region, Ürümqi and its surroundings in the Xinjiang province, which is not shown in the east China map, is also a hot spot of freight emission. Therefore, the significance of controlling emission from diesel freight trucks is greater considering the high impact on air quality and human health in the key regions.

Figure 9 shows more detailed emissions inventories of diesel freight trucks in the three biggest economic circles, Jing-Jin-Ji, Yangtze River Delta and Pearl River Delta, with a resolution of $0.1 \times 0.1^{\circ}$ per cell. The emission map indicated that cities with developed road networks and their surroundings suffered the most from the emissions of freight trucks. The distributions in the three districts were not the same. Pearl River Delta had the highest density of emissions. The high emissions area is close to Guangzhou and Shenzhen, the core cities in PRD. Meanwhile, in Yangtze River Delta the emissions are much more dispersed due to the large numbers of cities with high economic growth and well-developed road networks. From the differences in the emission distribution we can conclude that emissions from freight trucks in PRD are more aggregate.

\subsection{Comparisons with other studies}

$\mathrm{NO}_{\mathrm{x}}$ emission from this research is $28 \%$ higher than the MEP's estimation of 3.9 million tonnes $\mathrm{NO}_{\mathrm{x}}$ emissions from trucks in 2011 (MEP, 2012b). According to the MEP, the total $\mathrm{PM}_{2.5}$ emissions from the truck fleet were $460000 \mathrm{t}$ in 2011 (MEP, 2012a), which is $130 \%$ higher than the estimations in this research. The differences come from method, basic data and major assumptions.
Table 3. Uncertainty scales of inputs.

\begin{tabular}{ccccc}
\hline Stock & Annual & \multicolumn{2}{c}{ Emission factor } & Mileage \\
\cline { 3 - 4 } & $\begin{array}{c}\text { kilometers } \\
\text { traveled }\end{array}$ & $\mathrm{NO}_{\mathrm{x}}$ & $\mathrm{PM}_{2.5}$ & distribution \\
\hline $2 \%$ & $15 \%$ & -41 to $+79 \%$ & -31 to $+58 \%$ & $5 \%$ \\
\hline
\end{tabular}

Briefly stated, MEP estimated vehicle emissions on the basis of local vehicle stock, activity level and emission factors. The truck classification is the same with our study, according to gross vehicle weight and the national emission standards. For each group, the emission equals the product of local registration number, kilometer traveled per vehicle and emission factor. Adding up emissions of each group is the total emission. The emission factor that MEP used is based on the national emission standard. Detailed information of emission standards in China is shown in SI, Table S2. However, no further input data related to vehicle kilometer traveled were provided in this inventory.

The difference in $\mathrm{NO}_{\mathrm{x}}$ emissions was mainly caused by emission factors used in these two studies. In our study, the emission factor of China 3 trucks was not improved compared with China 2 (Wu et al., 2012; Liu et al., 2009). Thus, compared with MEP inventory and other inventory based on low $\mathrm{NO}_{\mathrm{x}}$ emission rate, our $\mathrm{NO}_{\mathrm{x}}$ emission is much higher.

Compared with MEP results, the $\mathrm{PM}_{2.5}$ emissions calculated in this research are significantly lower. A major reason for this lower result is that we included the decreasing trend of mileage traveled by trucks per year in this calculation. In China, overloading was common for commercial trucks. This accelerated the deterioration of trucks, which means older trucks had to run less due to deteriorated performance and more frequent repair and maintenance. The decrease of VKT was proved by our questionnaire investigation. If the mileage variation with age were omitted, the calculated $\mathrm{PM}_{2.5}$ emissions would increase $50 \%$, exceeding $300000 \mathrm{t}$. However, the VKT variation is not such a large problem for $\mathrm{NO}_{\mathrm{x}}$ because the $\mathrm{NO}_{\mathrm{x}}$ emission factor did not improve from old trucks to new trucks.

The provincial level $\mathrm{NO}_{\mathrm{x}}$ and $\mathrm{PM}_{2.5}$ emissions from road freight transportation are shown in Fig. 10a and b, respectively, ranking from the highest to the lowest. For both $\mathrm{NO}_{\mathrm{x}}$ and $\mathrm{PM}_{2.5}$, Shandong and Guangdong, where most of the freight transportation in China is conducted, take the leading positions in freight-truck emissions. The $\mathrm{NO}_{\mathrm{x}}$ and $\mathrm{PM}_{2.5}$ emissions in these two provinces exceeded 600000 and $25000 \mathrm{t}$, respectively. Provincial emissions from MEP inventory are also shown in Fig. 10. The provincial differences between the outcomes of the REIB approach and MEP inventories are obvious. The greatest differences are 220 and $-72 \%$ for $\mathrm{NO}_{\mathrm{x}}$ and $\mathrm{PM}_{2.5}$, respectively (REIB compared with MEP inventory). Not only do the emission scales differ but discrepancies also exist in the rankings of provinces. The differ- 


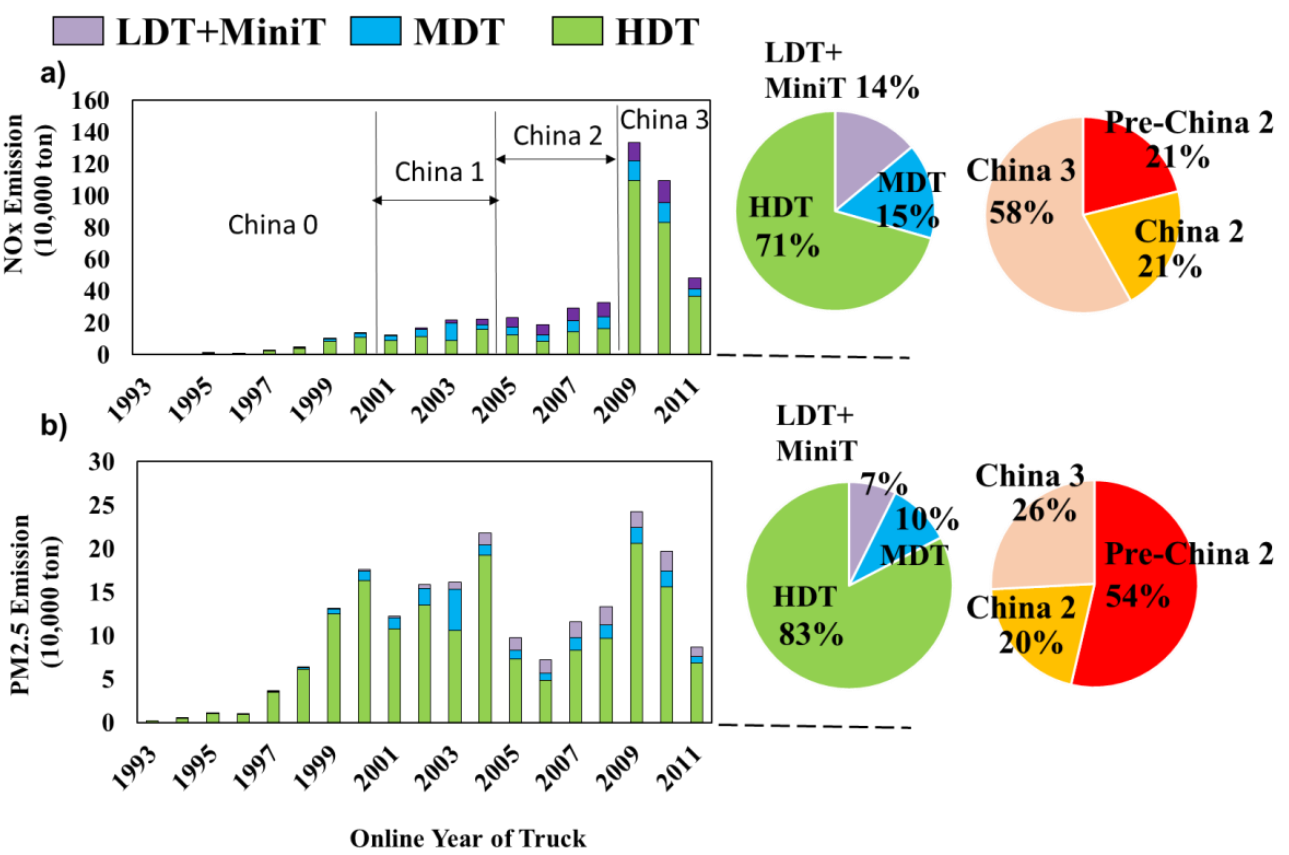

Figure 7. Emissions from diesel-truck fleet in 2011, China: (a) $\mathrm{NO}_{\mathrm{x}}$ emissions and (b) $\mathrm{PM}_{2.5}$ emissions.

a)

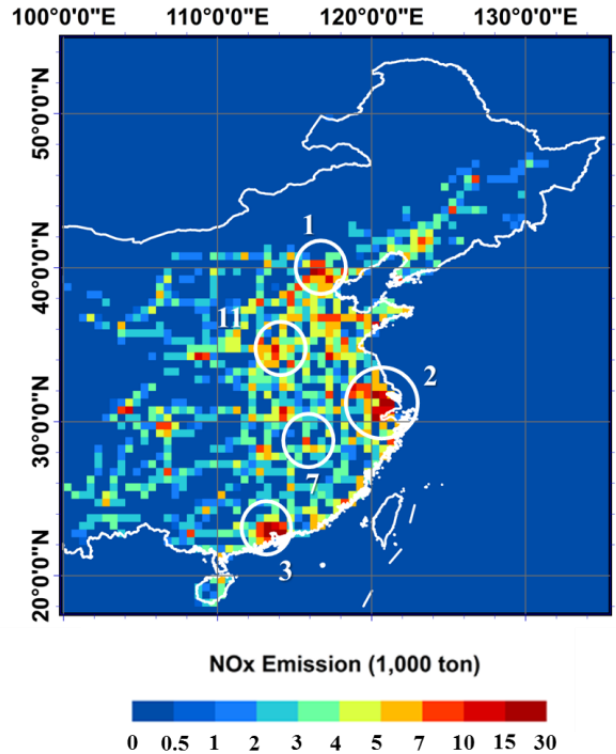

b)

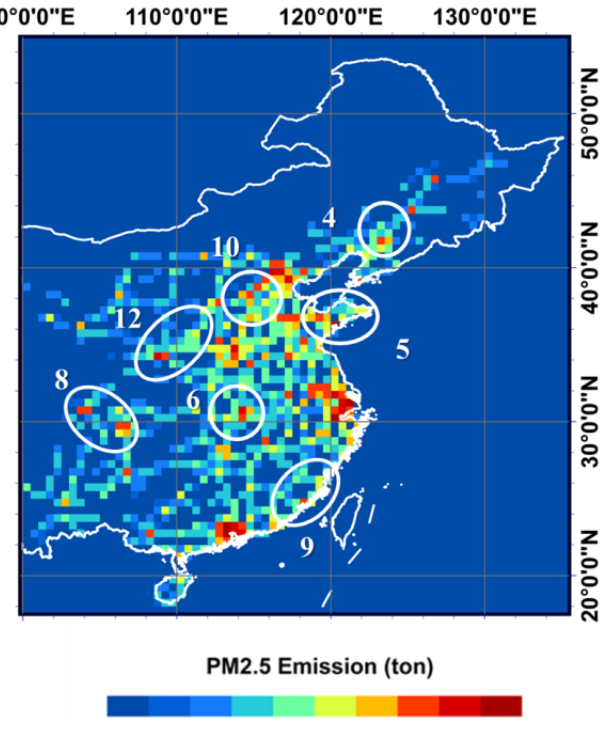

$0 \quad 25 \quad 501001502002503005007501,200$

Figure 8. Maps of $\mathrm{NO}_{\mathrm{x}}$ and $\mathrm{PM}_{2.5}$ emissions from freight trucks in the eastern part of China in 2011: (a) $\mathrm{NO}_{\mathrm{x}}$ emissions and (b) $\mathrm{PM}_{2.5}$ emissions. Key control areas in 12th 5-year plan of air-pollution control: (1) Jing-Jin-Ji, (2) Yangtze River Delta, (3) Pearl River Delta, (4) central part of Liaoning province, (5) Shandong province, (6) Wuhan and its surroundings, (7) Changsha-Zhuzhou-Changde, (8) Chengdu and Chongqing, (9) west side of the Taiwan strait, (10) central and northern part of Shanxi province, (11) Guanzhong region in Shaanxi, (12) Gansu and Ningxia.

ences come from both different basic data and different methods. To avoid influence from input data, we re-calculated provincial VKT using our method and the traditional approach. Here the traditional approach means calculating total VKT based on local registration data and average mileage traveled. The differences between the provincial proportions of VKT are shown in Fig. 11. Taking Shanghai as an example, REIB method has $39.9 \%$ lower VKT compared with the traditional method. In the report published by MEP (2012a), the largest contributor of both $\mathrm{NO}_{\mathrm{x}}$ and $\mathrm{PM}_{2.5}$ in China during 2011 was the Hebei province. However, Shandong contributed the most road freight emissions in 2011 according to 


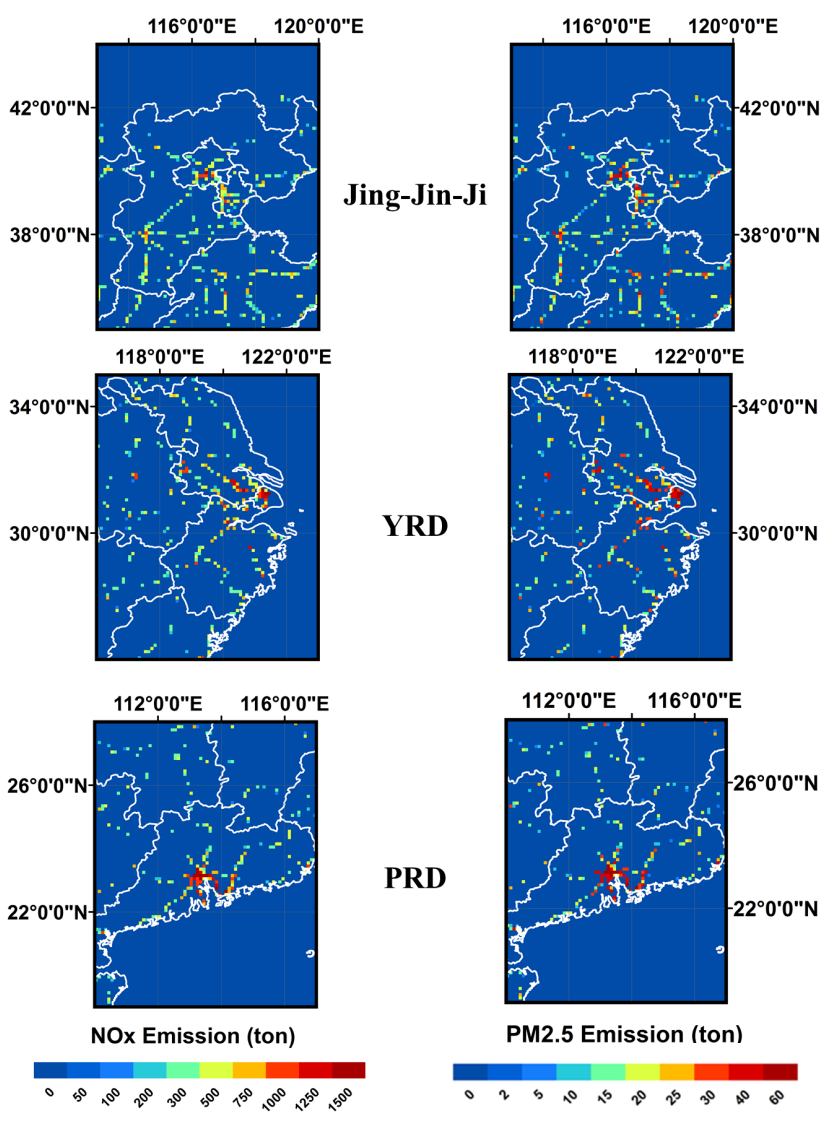

Figure 9. Maps of $\mathrm{NO}_{\mathrm{x}}$ and $\mathrm{PM}_{2.5}$ emissions from freight trucks in the eastern part of China in 2011.

this research. This difference was caused by the methodology on which the inventory was based. As discussed earlier, the registration-number-based approaches have a significant bias because trucks are not limited to the province where they are registered. Therefore, a province with the largest registration number of trucks might not have the most freight transportation. According to the National Bureau of Statistics (2013), Shandong has the greatest cargo volume and cargo turnover volume in the road transportation sector. These data verified our assumption from a different perspective. Therefore, the former approach would be inaccurate without considering that the real range of truck activities might be different from the place where they are registered. There is an assumption in the REIB approach that the same type of roads have equal congestion in different provinces. This is a limitation of our study mainly because of the limited data amount. This limitation could be avoided if future GPS data could be sufficient to characterize driving conditions in each province, which means that the REIB approach is still suitable for future massive data analysis. We can still trust the results because the differences among the same types of roads are less significant than among different types.

\subsection{Uncertainty analysis}

A Monte Carlo simulation is used to quantify the uncertainty in both $\mathrm{NO}_{\mathrm{x}}$ and primary $\mathrm{PM}_{2.5}$ emissions from diesel freight trucks. Monte Carlo methods are widely used in identifying uncertainties in emission inventories (Hammersley and Handscomb, 1964; Sawyer et al., 2000; Wang et al., 2008b). The simulation is based on activity data and emission factors variety distribution. The statistical distributions of the annual kilometers traveled and stock are determined according to Zhang et al. (2013). And the uncertainty of mileage distribution was estimated according to our questionnaire results. For uncertainties of emission factors we used the standard errors in the emission measurements to represent the uncertainties (Wang et al., 2012; Zhang et al., 2013). Considering that the activity-level data are estimated based upon survey since it is not available through official channels, there is inevitable systematic bias in the estimation (Zheng et al., 2009). The uncertainties of the input parameters are listed in Table 3 . The distribution of the inputs follows normal distribution. The trials of the simulation were set to 100000 times.

The overall uncertainties in this inventory are estimated at -24.1 to $44.7 \%$ for $\mathrm{NO}_{\mathrm{x}}$ emissions and -16.3 to $31.3 \%$ for primary $\mathrm{PM}_{2.5}$ emissions. The uncertainty is significant compared with other types of anthropogenic emissions because the uncertainties in both activity level and emission factor of mobile sources are more significant than other types of sources. The greatest uncertainties in the simulation are the uncertainties of emission factors of freight trucks. The uncertainties were significant during the test procedure. The emission data from the on-board measurement of diesel freighttruck emissions have significant variances that even reached $100 \%$ in some cases (Huo et al., 2012a). In this study, comprehensive research into the activity levels of freight trucks was conducted to minimize the uncertainties in activity level. The new REIB approach also reduced the uncertainties in the distribution of freight-truck activity. Further improvements can be achieved by more accurate measurements on emission factors.

\section{Conclusions}

We presented a REIB approach to estimate $\mathrm{NO}_{\mathrm{x}}$ and $\mathrm{PM}_{2.5}$ emissions in China in 2011. The estimated emissions inventory may be used to forecast and evaluate the impact of road freight transportation on air quality in China. Unlike approaches that are based on the local registration numbers of trucks, the REIB approach views the freight system as a whole nationwide system. The activity of freight trucks is distributed according to the development and infrastructure of the local road system. The REIB approach is feasible in the freight transportation sector, because in many cases, freight trucks conduct long-distance trips across several provinces, neglecting where they are registered. The dis- 
a)

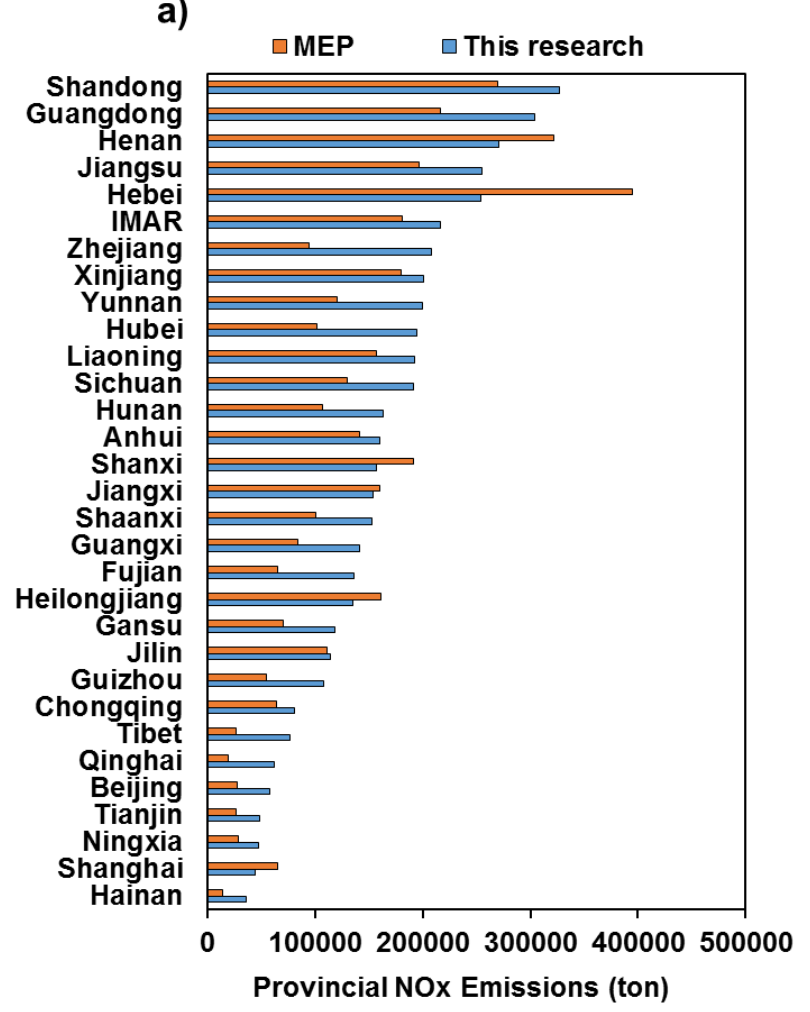

b)

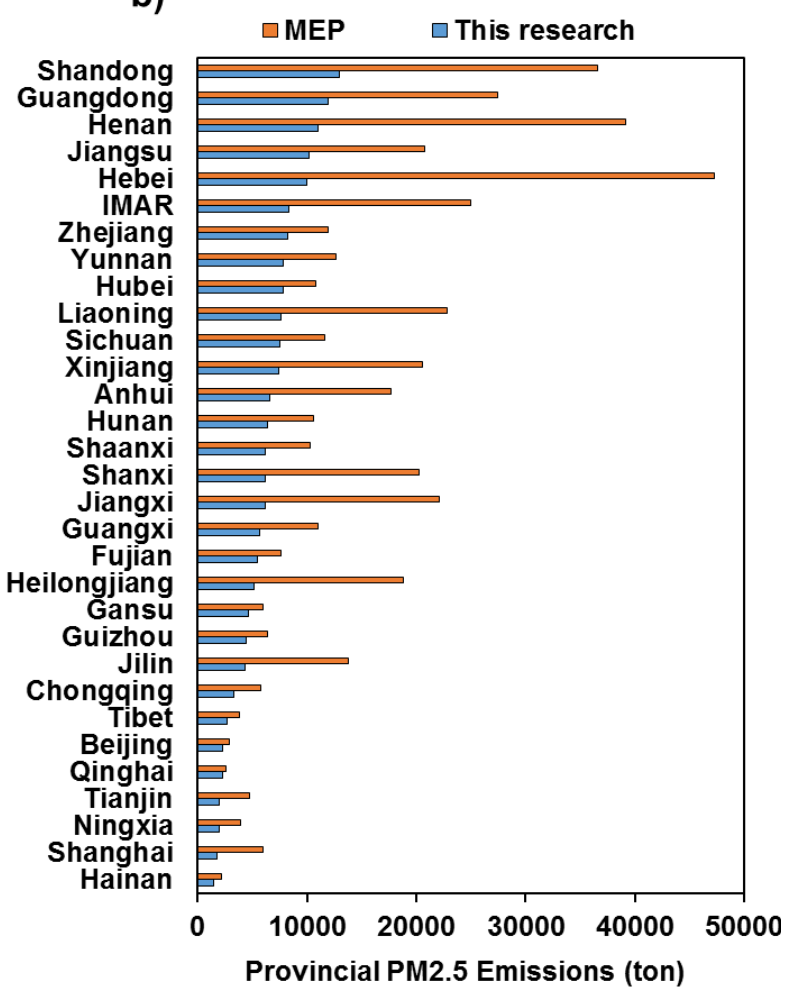

Figure 10. Provincial diesel-truck emissions from this study and MEP inventories: (a) $\mathrm{NO}_{\mathrm{x}}$ emissions ranks and (b) $\mathrm{PM}_{2.5}$ emissions ranks (ranking according to emission scales in this research).

tribution of emissions among the different provinces has significant differences compared to the former research that was based on local registration numbers. However, the REIB approach would be less beneficial when applied to the passenger car sector because private cars tend to have a more local range of activity.

According to the GPS monitoring results, the driving conditions on the different types of road are different for trucks. These differences would lead to significant variances in emission factors. According to the simulation results by the IVE model that were interpolated with local on-board test data in China, the differences between the emission factors from different types of trucks of same emissions standard could reach as high as 70 and $50 \%$ for $\mathrm{NO}_{\mathrm{x}}$ and $\mathrm{PM}_{2.5}$, respectively. Uncertainties in emission factors are the major drivers of the total uncertainty in the emissions inventory of diesel freight trucks. The improvements of emission factors on the different roads reduce the uncertainty and inaccuracy of diesel freight-truck emissions.

In 2011, the diesel-truck fleet emitted 5.0 (4.8-7.2) million tonnes $\mathrm{NO}_{\mathrm{x}}$ and $0.20(0.17-0.22)$ million tonnes primary $\mathrm{PM}_{2.5}$ in China. According to our research, the failure of reducing $\mathrm{NO}_{\mathrm{x}}$ emission of the China 3 diesel trucks is the main reason for total high $\mathrm{NO}_{\mathrm{x}}$ emissions. The challenge of $\mathrm{NO}_{\mathrm{x}}$ reduction will last for many years until all existing trucks are replaced by new trucks with an after-treatment system. Moreover, locations with the highest diesel freight-truck emission density are the regions with the most severe air-quality problems. In addition, 12 out of the 13 key air-quality control areas listed in the 12th FYP of air-pollution control in key regions have high densities of truck emissions. Therefore, controlling diesel-truck emissions plays a critical role in the air-quality control plan in China. According to our emission distribution in 2011 of the fleet by vehicle age, promoting more stringent emission standard on new trucks is more efficient than eliminating the old yellow-label trucks. However, the fact is that the Chinese government postponed the application of the China 4 diesel-truck emissions standard nationwide several times in the past few years.

Our research also indicates the uncertainties in freighttruck emissions are approximately from -24.1 to $+44.7 \%$ for $\mathrm{NO}_{\mathrm{x}}$ and from -16.3 to $+31.3 \%$ for $\mathrm{PM}_{2.5}$. The uncertainties mainly come from the uncertainties in the emission factors from on-board measurements. Via improvements in specifying the emission factors to road type levels, this research reduced the uncertainties in freight-truck inventories.

The Supplement related to this article is available online at doi:10.5194/acp-15-2105-2015-supplement. 


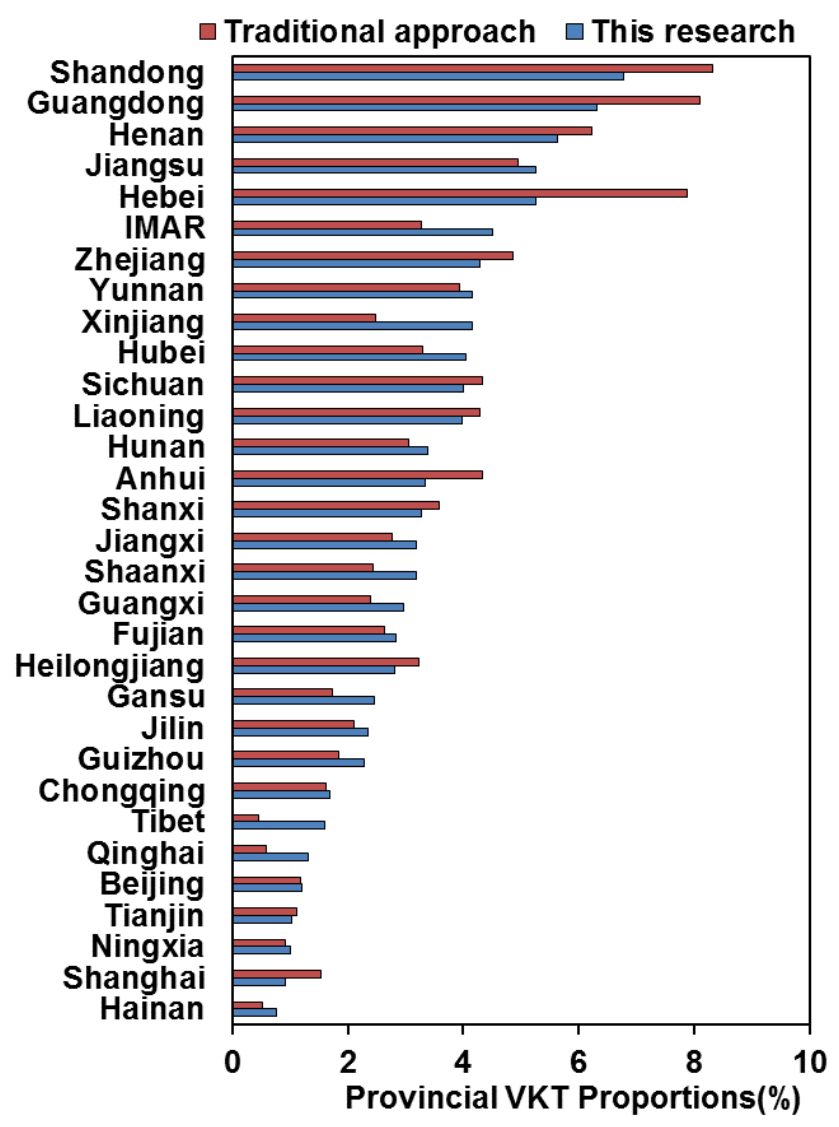

Figure 11. Provincial VKT proportions from the REIB approach and traditional approach.

Acknowledgements. This work is supported by the National Natural Science Foundation of China (71101078), the National High Technology Research and Development Program of China (2013AA065303D) and the National Program on Key Basic Research Project (2014CB441301). Xiaofan Yang receives support from Energy Foundation. In addition, these data collection programs would not have occurred without local partners in the cities of study.

Edited by: T. Bond

\section{References}

Beaton, S. P., Bishop, G. A., Zhang, Y., Ashbaugh, L. L., Lawson, D. R., and Stedman, D. H.: On-road vehicle emissions: regulations, costs, and benefits, Science, 268, 991-993, 1995.

Box, G. E., Hunter, J. S., and Hunter, W. G.: Statistics for experimenters, Wiley New York, 2005.

Cai, H. and Xie, S.: Estimation of vehicular emission inventories in China from 1980 to 2005, Atmos. Environ, 41, 8963-8979, 2007.

Canagaratna, M. R., Jayne, J. T., Ghertner, D. A., Herndon, S., Shi, Q., Jimenez, J. L., Silva, P. J., Williams, P., Lanni, T., and Drewnick, F.: Chase studies of particulate emissions from in-use New York City vehicles, Aerosol Sci. Tech., 38, 555-573, 2004.
CATARC: China Automotive Industry Yearbook, China Industry Press, Beijing, 2012.

Chan, A. P., Lam, P. T., Chan, D. W., Cheung, E., and Ke, Y.: Drivers for adopting public private partnerships - empirical comparison between China and Hong Kong special administrative region, J. Constr. Eng. M. ASCE, 135, 1115-1124, 2009.

CE-CERT (Center for Environmental Research and Technology, College of Engineering, University of California at Riverside), GSSR (Global Sustainable Systems Research), ISSRC (the International Sustainable Systems Research Center): IVE Model User Manual: Version 2.0 Attachment B and Attachment C, available at www.issrc.org/ive (last access: 1 May 2014), 2008.

Fu, L., Hao, J., He, D., He, K., and Li, P.: Assessment of vehicular pollution in China, J. Air Waste Manage., 51, 658-668, 2001.

Hammersley, J. M. and Handscomb, D. C.: Monte carlo methods, Chapman and Hall, London, 1964.

Hammitt, J. K. and Zhou, Y.: The economic value of air-pollutionrelated health risks in China: a contingent valuation study, Environ. Res. Econ., 33, 399-423, 2006.

Hao, H., Wang, H., Ouyang, M., and Cheng, F.: Vehicle survival patterns in China, Sci. China Technol. Sc., 54, 625-629, 2011.

Hine, J., Barton, A., Guojing, C., and Wenlong, W.: The scope for improving the efficiency of road freight transport in china, 7th World Conference on Transport Research, Sidney, Australia, July, 1995.

Holguin-Veras, J., Wang, Q., Xu, N., Ozbay, K., Cetin, M., and Polimeni, J.: The impacts of time of day pricing on the behavior of freight carriers in a congested urban area: Implications to road pricing, Transport. Res. A-Pol., 40, 744-766, 2006.

Huo, H., Yao, Z., Zhang, Y., Shen, X., Zhang, Q., and He, K.: On-board measurements of emissions from diesel trucks in five cities in China, Atmos. Environ., 54, 159-167, doi:10.1016/j.atmosenv.2012.01.068, 2012a.

Huo, H., Zhang, Q., He, K., Yao, Z., and Wang, M.: Vehicle-use intensity in China: Current status and future trend, Energ. Policy, 43, 6-16, doi:10.1016/j.enpol.2011.09.019, 2012b.

Jimenez-Palacios, J. L.: Understanding and quantifying motor vehicle emissions with vehicle specific power and TILDAS remote sensing, Massachusetts Institute of Technology, Cambridge, 1998.

Kamakaté, F. and Schipper, L.: Trends in truck freight energy use and carbon emissions in selected OECD countries from 1973 to 2005, Energ. Policy, 37, 3743-3751, 2009.

Koupal, J., Landman, L., Nam, E., Warila, J., Scarbro, C., Glover, E., and Giannelli, R.: MOVES2004 energy and emission inputs (Draft report). Prepared for US Environmental Protection Agency, EPA-420-P-05-003, Washington, DC, 2005.

Lajunen, T., Parker, D., and Summala, H.: The Manchester Driver Behaviour Questionnaire: a cross-cultural study, Accident Anal. Prev., 36, 231-238, doi:10.1016/S0001-4575(02)00152-5, 2004.

Liu, H., He, K., and Wang, Q.: Vehicular emissions inventory and influencing factors in Tianjin, Journal-Tsinghua University, 48, 370, 2008.

Liu, H., He, K., Lents, J. M., Wang, Q., and Tolvett, S.: Characteristics of diesel truck emission in China based on portable emissions measurement systems, Environ. Sci. Technol., 43, 9507-9511, 2009. 
Matus, K., Nam, K.-M., Selin, N. E., Lamsal, L. N., Reilly, J. M., and Paltsev, S.: Health damages from air pollution in China, Global Environ. Chang., 22, 55-66, 2012.

MEP (Ministry of Environmental Protection): China Vehicular Pollution Prevention Annual Report 2012, available at: http:// www.mep.gov.cn/gkml/hbb/qt/201212/t20121227_244340.htm (last access: 1 February 2015), 2012a.

MEP (Ministry of Environmental Protection): NDRC (National Development and Reform Commision), MOF (Ministry of Finance): 12th Five Year Plan of Air Pollution Control in Key Regions, available at: http://www.mep.gov.cn/gkml/hbb/ bwj/201212/t20121205_243271.htm (last access: 1 February 2015), $2012 b$.

Moreno, C., Carvalho, F., Lorenzi, C., Matuzaki, L., Prezotti, S., Bighetti, P., Louzada, F., and Lorenzi-Filho, G.: High risk for obstructive sleep apnea in truck drivers estimated by the Berlin questionnaire: prevalence and associated factors, Chronobiol. Int., 21, 871-879, 2004.

Moreno, C., Louzada, F., Teixeira, L., Borges, F., and Lorenzi-Filho, G.: Short sleep is associated with obesity among truck drivers, Chronobiol. Int., 23, 1295-1303, 2006.

National Bureau of Statistics, China Statistics Yearbook, China Statistics Press, Beijing, 2013.

Ochieng, W., Polak, J., Noland, R., Park, J.-Y., Zhao, L., Briggs, D., Gulliver, J., Crookell, A., Evans, R., and Walker, M.: Integration of GPS and dead reckoning for real-time vehicle performance and emissions monitoring, GPS Solut., 6, 229-241, 2003.

Ohara, T., Akimoto, H., Kurokawa, J., Horii, N., Yamaji, K., Yan, X., and Hayasaka, T.: An Asian emission inventory of anthropogenic emission sources for the period 1980-2020, Atmos. Chem. Phys., 7, 4419-4444, doi:10.5194/acp-7-4419-2007, 2007.

Rakha, H., Ahn, K., and Trani, A.: Development of VT-Micro model for estimating hot stabilized light duty vehicle and truck emissions, Transport. Res. D-Tr. E., 9, 49-74, 2004.

Sawyer, R. F., Harley, R. A., Cadle, S. H., Norbeck, J. M., Slott, R., and Bravo, H. A.: Mobile sources critical review: 1998 NARSTO assessment, Atmos. Environ., 34, 2161-2181, doi:10.1016/s1352-2310(99)00463-x, 2000.

Streets, D., Bond, T., Carmichael, G., Fernandes, S., Fu, Q., He, D., Klimont, Z., Nelson, S., Tsai, N., and Wang, M. Q.: An inventory of gaseous and primary aerosol emissions in Asia in the year 2000, J. Geophys. Res.-Atmos., 108, GTE30.1-30.23, doi:10.1029/2002JD003093, 2003.
Sullman, M. J. M., Meadows, M. L., and Pajo, K. B.: Aberrant driving behaviours amongst New Zealand truck drivers, Transport. Res. F-Traf., 5, 217-232, doi:10.1016/S1369-8478(02)00019-0, 2002.

Wang, H., Chen, C., Huang, C., and Fu, L.: On-road vehicle emission inventory and its uncertainty analysis for Shanghai, China, Sci. Total Environ., 398, 60-67, doi:10.1016/j.scitotenv.2008.01.038, 2008a.

Wang, H., Chen, C., Huang, C., and Fu, L.: On-road vehicle emission inventory and its uncertainty analysis for Shanghai, China, Sci. Total Environ., 398, 60-67, 2008b.

Wang, X., Westerdahl, D., Hu, J., Wu, Y., Yin, H., Pan, X., and Max Zhang, K.: On-road diesel vehicle emission factors for nitrogen oxides and black carbon in two Chinese cities, Atmos. Environ., 46, 45-55, doi:10.1016/j.atmosenv.2011.10.033, 2012.

Wu, Y., Wang, R., Zhou, Y., Lin, B., Fu, L., He, K., and Hao, J.: On-Road Vehicle Emission Control in Beijing: Past, Present, and Future†, Environ. Sci. Technol., 45, 147-153, doi:10.1021/es1014289, 2010.

Wu, Y., Zhang, S. J., Li, M. L., Ge, Y. S., Shu, J. W., Zhou, Y., Xu, Y. Y., Hu, J. N., Liu, H., Fu, L. X., He, K. B., and Hao, J. M.: The challenge to $\mathrm{NO}_{x}$ emission control for heavy-duty diesel vehicles in China, Atmos. Chem. Phys., 12, 9365-9379, doi:10.5194/acp12-9365-2012, 2012.

Xie, C.-Q. and Parker, D.: A social psychological approach to driving violations in two Chinese cities, Transport. Res.-F-Traf, 5, 293-308, 2002.

Zhang, Q., He, K., and Huo, H.: Policy: cleaning China's air, Nature, 484, 161-162, 2012.

Zhang, S., Wu, Y., Wu, X., Li, M., Ge, Y., Liang, B., Xu, Y., Zhou, Y., Liu, H., and Fu, L.: Historic and future trends of vehicle emissions in Beijing, 1998-2020: A policy assessment for the most stringent vehicle emission control program in China, Atmos. Environ., 89, 216-229, doi:10.1016/j.atmosenv.2013.12.002, 2013.

Zheng, B., Huo, H., Zhang, Q., Yao, Z. L., Wang, X. T., Yang, X. F., Liu, H., and He, K. B.: A new vehicle emission inventory for China with high spatial and temporal resolution, Atmos. Chem. Phys. Discuss., 13, 32005-32052, doi:10.5194/acpd-13-320052013, 2013.

Zheng, J., Zhang, L., Che, W., Zheng, Z., and Yin, S.: A highly resolved temporal and spatial air pollutant emission inventory for the Pearl River Delta region, China and its uncertainty assessment. Atmos. Environ., 43, 5112-5122, 2009. 